\title{
Osteoporosis International
}

\section{Effect of whole-body vibration training on bone mass in adolescents with and without Down syndrome: a randomized controlled trial

\author{
--Manuscript Draft--
}

\begin{tabular}{|c|c|c|}
\hline Manuscript Number: & \multicolumn{2}{|l|}{ OSIN-D-15-00365R1 } \\
\hline Full Title: & \multicolumn{2}{|c|}{$\begin{array}{l}\text { Effect of whole-body vibration training on bone mass in adolescents with and without } \\
\text { Down syndrome: a randomized controlled trial }\end{array}$} \\
\hline \multirow[t]{2}{*}{ Funding Information: } & $\begin{array}{l}\text { Ministerio de Educación Cultura y } \\
\text { Deportes } \\
\text { (AP12-2854) }\end{array}$ & Mr. Ángel Matute-Llorente \\
\hline & $\begin{array}{l}\text { Fondo Europeo de Desarrollo Regional } \\
\text { (MICINN-FEDER) }\end{array}$ & Not applicable \\
\hline Abstract: & \multicolumn{2}{|c|}{ 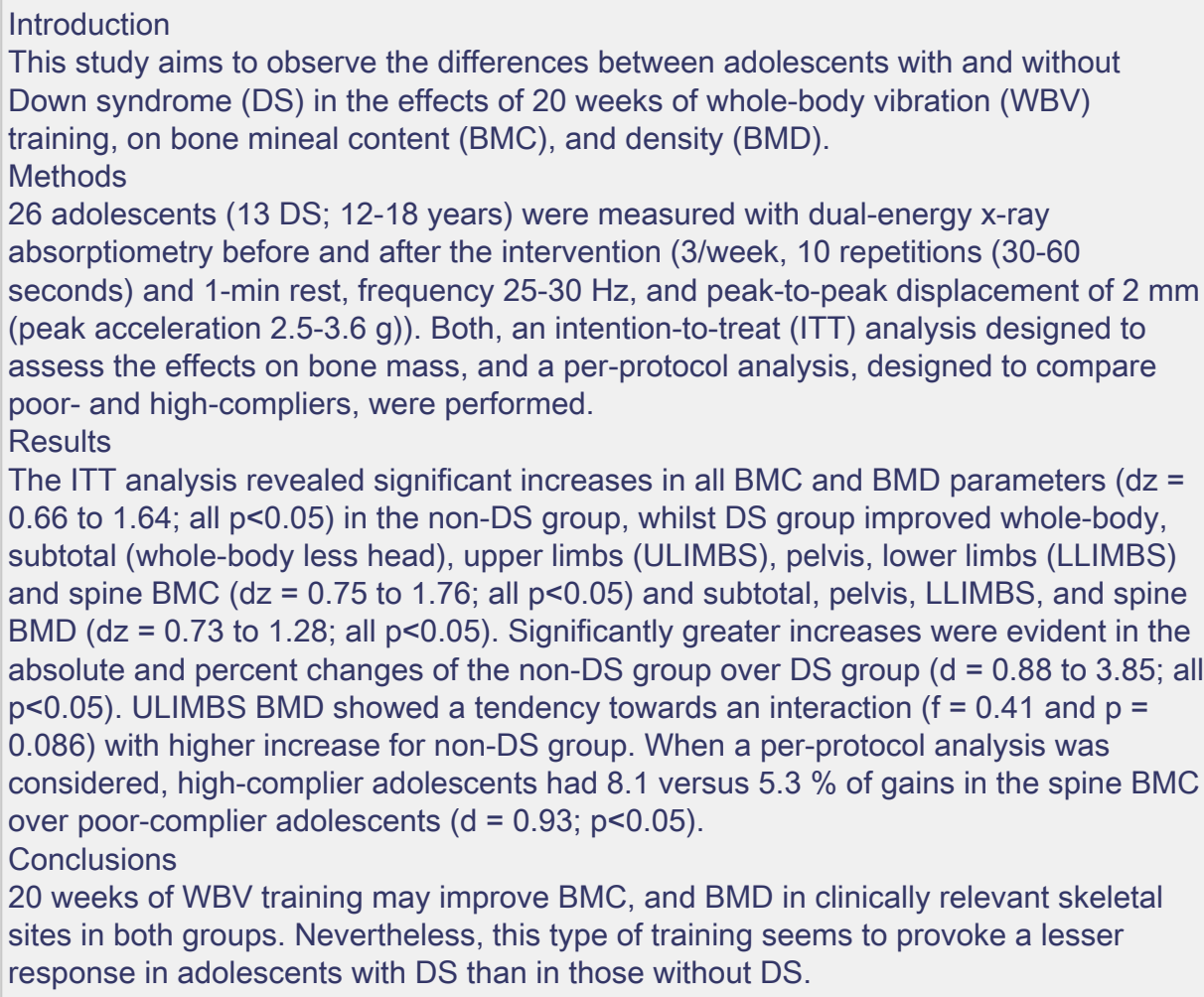 } \\
\hline Corresponding Author: & \multicolumn{2}{|l|}{$\begin{array}{l}\text { José Antonio Casajús, Ph.D., M.D. } \\
\text { SPAIN }\end{array}$} \\
\hline \multicolumn{3}{|c|}{$\begin{array}{l}\text { Corresponding Author Secondary } \\
\text { Information: }\end{array}$} \\
\hline \multicolumn{3}{|c|}{ Corresponding Author's Institution: } \\
\hline \multicolumn{3}{|c|}{$\begin{array}{l}\text { Corresponding Author's Secondary } \\
\text { Institution: }\end{array}$} \\
\hline First Author: & \multicolumn{2}{|l|}{ Ángel Matute-Llorente, M.Sc. } \\
\hline \multicolumn{3}{|c|}{ First Author Secondary Information: } \\
\hline \multirow[t]{2}{*}{ Order of Authors: } & \multicolumn{2}{|l|}{ Ángel Matute-Llorente, M.Sc. } \\
\hline & \multicolumn{2}{|l|}{ Alejandro González-Agüero, Ph.D } \\
\hline
\end{tabular}


Alba Gómez-Cabello, Ph.D
Julio Tous-Fajardo, Ph.D

Germán Vicente-Rodríguez, Ph.D

José Antonio Casajús, Ph.D., M.D.

Order of Authors Secondary Information:

Author Comments:

Tuesday, June 16, 2015

Dear Editor,

Please, find attached a revised version of our manuscript entitled "Effect of whole-body vibration training on bone mass in adolescents with and without Down syndrome: a randomized controlled trial" to be reconsidered for publication in your prestigious journal.

We have taken into account all the comments made from the reviewer and a point-bypoint response has been attached to our submission. In addition, we have highlighted in yellow the pertinent changes in the main manuscript for an easier revision.

This manuscript represents original unpublished material; is not under consideration for publication elsewhere, and further, it will not be submitted for publication elsewhere until a decision is made regarding its acceptability for publication in your Journal. All authors have read and approved of this final version, are responsible for the reported research and have contributed significantly to the research of the present manuscript.

There are no conflicts of interest and financial disclosures for any author of this manuscript. None of the authors have any financial interest.

Sincerely yours,

Jose A Casajús, M.D., Ph.D.

Faculty of Health and Sport Sciences

University of Zaragoza

Response to Reviewers:

Comments for the Author:

Reviewer \#1: Manuscript ID: OSIN-D-15-00365

The manuscript presented by Matute-Llorente and colleagues is clearly of interest to people working in all health related disciplines. The manuscript provides an interesting argument in the understanding of the relationship between Down syndrome changes in bone mass after vibration training. The structure of the document is well written and follows an appropriate structure that makes for an easy, detailed and informative read. Response: Thank you very much for your revision of our manuscript. All your comments have been addressed and explained below. Also, the changes have been highlighted in yellow in the manuscript in order to make easier the revision process.

\section{MINOR CONCERNS:}

P4L49 how will gender impact the changes in BMD between these two groups? $\mathrm{R}$ : Thanks for your comment, we have realised the excessive length and lack of clarity in that sentence. This sentence has been reworded in order to clarify that these studies were not comparing gender groups, but instead are completely different studies. The sentence states like this now:

Results on WBV therapies are not entirely clear; some studies have shown increases in BMC at the lumbar spine [17], and areal BMD at the femur [18, 19] and the spine [19-21] in different disabled populations. On the other hand, changes on bone parameters were not present nor in osteopenic girls with adolescent idiopathic scoliosis [22] neither in children with Duchene muscular dystrophy [23] with a similar WBV therapy.

P5L49 the authors first use of a table is "Table 2" ? Table 1 is not mentioned until later pages.

R: thanks, that was a typo due to swap paragraphs after naming Tables. The paragraph involving WBV intervention has been moved above the one on the participants. Table 1 is now mentioned earlier than table 2. 
P6L41 how was a 90 degree knee angle measured and maintained during the vibration intervention? how can the researchers be confident that this was the case for all subjects ? were the subjects allowed to hold onto a rail during the vibration intervention $?$

R: The angle was not measured but it was observed and controlled by a specialist. There were no problems in squatting position working with non-DS group, all participants performed the exercise properly. The researchers are confident with exercise realization because all participants (with and without DS) were accompanied by a researcher in each training. The researcher was competent on the squatting technique due to the appropriate training, he provided verbal feedbacks when spotted a mistake. Participants were allowed to hold onto a strap during the vibration intervention. This has been added onto the manuscript.

P6L42 did the authors consider body composition and body position changing the dissipation of the vibration signal through the body and possibly impacting the changes to BMD/BMC?

R: Yes we did. Authors were aware of the possible vibration dissipation throughout the body due to the squatting position; however, taking into account the special needs and learning difficulties of half of the participants, decide to use this easy and comfortable position. Also, being the first study with adolescents with DS we decided it would be safer to perform the therapy with a less aggressive protocol, compared with other for example standing on the platform.

P11L51 reword the sentence "For that reasons' ..."

R: Reworded.

"It seems therefore realistic to affirm that young persons with DS may benefit from WBV interventions in order to improve their body composition, specifically their bone mass."

References

Ref 38, 39, 42 incomplete and missing journal volume and page numbers

R: Ref 42 has been updated.

Refs 38 and 39 are still ahead of print.

Figures 2,3 these figures are repetitive as the data is available in the tables - not warranted and difficult to read.

$\mathrm{R}$ : Following the reviewer's advice, figures 2,3 have been deleted. 


\section{Effect of whole-body vibration training on bone mass in adolescents with and without}

\section{Down syndrome: a randomized controlled trial}

A. Matute-Llorente ${ }^{1,2}$, E-mail: amatute@unizar.es; A. González-Agüero ${ }^{1,3}$, E-mail: alg28@aber.ac.uk; A. Gómez-Cabello ${ }^{1,4}$, E-mail: agomez@unizar.es; J. Tous-Fajardo ${ }^{5-6}$, Email: jtous17@yahoo.com; G. Vicente-Rodríguez ${ }^{1,2}$, E-mail: gervicen@unizar.es; J.A.

Casajús ${ }^{1,2}$, E-mail: joseant@unizar.es

${ }^{1}$ GENUD (Growth, Exercise, Nutrition and Development) Research Group

University of Zaragoza C/Pedro Cerbuna $\mathrm{n}^{\circ} 12,50009$, Zaragoza, Spain

${ }^{2}$ Faculty of Health and Sport Science (FCSD), Department of Physiatry and Nursing

Universidad de Zaragoza Ronda Misericordia 5, 22001-Huesca, Spain

${ }^{3}$ Department of Sport and Exercise Science

Aberystwyth University Ceredigion, UK

${ }^{4}$ Centro Universitario de la Defensa

Zaragoza, Spain

${ }^{5}$ Juventus Football Club

Turin, Italy

${ }^{6}$ Sports Performance Lab, Sport Sciences Research Group

INEFC Av. de l'Estadi 12, 08038 Barcelona, Spain

*Corresponding author: José Antonio Casajus, e-mail: joseant@unizar.es

GENUD Research Group

C/Pedro Cerbuna $n^{\circ} 12$

50009 Zaragoza, Spain.

Phone: +34 876533755 


\begin{abstract}
Summary

Whole body vibration training (WBV) attracts great interest as osteoporosis prevention strategy. Twenty-six adolescents with and without Down syndrome (13 DS; 12-18 years) performed 20 weeks of WBV. The results indicate that WBV seems to provoke a lesser response in adolescents with DS than in those without DS.
\end{abstract}

Introduction

This study aims to observe the differences between adolescents with and without Down syndrome (DS) in the effects of 20 weeks of whole-body vibration (WBV) training, on bone mineal content (BMC), and density (BMD).

Methods

26 adolescents (13 DS; 12-18 years) were measured with dual-energy x-ray absorptiometry before and after the intervention (3/week, 10 repetitions (30-60 seconds) and 1-min rest, frequency $25-30 \mathrm{~Hz}$, and peak-to-peak displacement of $2 \mathrm{~mm}$ (peak acceleration 2.5-3.6 g)). Both, an intention-to-treat (ITT) analysis designed to assess the effects on bone mass, and a per-protocol analysis, designed to compare poor- and high-compliers, were performed.

Results

The ITT analysis revealed significant increases in all BMC and BMD parameters $(d z=0.66$ to 1.64; all $p<0.05)$ in the non-DS group, whilst DS group improved whole-body, subtotal (whole-body less head), upper limbs (ULIMBS), pelvis, lower limbs (LLIMBS) and spine $\mathrm{BMC}(d z=0.75$ to 1.76 ; all $p<0.05)$ and subtotal, pelvis, LLIMBS, and spine BMD $(d z=0.73$ to 1.28 ; all $p<0.05)$. Significantly greater increases were evident in the absolute and percent changes of the non-DS group over DS group $(d=0.88$ to 3.85 ; all $p<0.05)$. ULIMBS BMD showed a tendency towards an interaction $(f=0.41$ and $p=0.086)$ with higher increase for non-DS group. When a per-protocol analysis was considered, high-complier adolescents had 
8.1 versus $5.3 \%$ of gains in the spine BMC over poor-complier adolescents $(d=0.93$;

$p<0.05)$.

Conclusions

20 weeks of WBV training may improve BMC, and BMD in clinically relevant skeletal sites in both groups. Nevertheless, this type of training seems to provoke a lesser response in adolescents with DS than in those without DS.

\section{Keywords}

Bone health

Down's syndrome

Exercise

Osteoporosis

Vibration 


\section{Introduction}

The increase in the life expectancy of individuals with Down syndrome (DS) [1] is fostering the appearance of some illnesses such as osteopenia or osteoporosis that previously were not diagnosed in this population. These diseases generate an increased risk of suffering from a bone fracture because of low bone density [2]. Also, taken into account that lower levels of bone mineral content (BMC) and bone mineral density (BMD) have been found in DS population [3-8], and that a low BMD was described by Lips et al. [9] as one of the main factors involved in fracture risk, it might be said that individuals with DS are a population at risk. Thus, special attention should be given to improve bone mass in DS population by implementing specific lifestyle interventions (i.e. exercise and nutrition). In fact, a recent study has questioned the use of antiresorptive therapy in DS population and focused attention on increasing bone mass by other interventions like weight-bearing training [10]. It has been well documented that physical exercise is one of the best non-pharmacological ways to improve several health aspects [11] including bone mass [12]. Low-amplitude highfrequency whole body vibration (WBV) training is recently receiving much attention for treating low levels of bone mass [13]. Nowadays, WBV has been applied mainly as a therapy method in children and adolescents with disabling conditions [14] and also in seniors $[15,16]$. Results on WBV therapies are not entirely clear; some studies have shown increases in BMC at the lumbar spine [17], and areal BMD at the femur [18, 19] and the spine [19-21] in different disabled populations. On the other hand, changes on bone parameters were not present nor in osteopenic girls with adolescent idiopathic scoliosis [22] neither in children with Duchenne muscular dystrophy [23] with a similar WBV therapy. Nevertheless, the only common finding in almost every study was the lack of severe negative side effects [14, 20, $21,23,24]$ after the WBV interventions. For that reason, WBV has been defined as a welltolerated training method which may be used as an intervention to increase bone health in 
people with DS. Some efforts have been made on studying bone mass in DS populations [47], also focusing on the effects of some physical training interventions [25-28]. Despite this, information concerning body composition, specially bone mass, in youths with DS is scarce [29]. Furthermore, the fact that DS is a genetic condition, with possibly different expression in many genes, may have a direct influence in the adaptive response to WBV training. For this reason, it is also possible that musculoskeletal system of non-disabled populations may be or not as responsive to this type of training.

Therefore, the main aim of this study was to observe the differences between adolescents with and without DS in the effects of a WBV training program, on BMC and BMD. It was hypothesized that 20-weeks of WBV will show greater improvements in bone mass of adolescents with DS compared with those without.

\section{Material and methods}

The study design, protocol and consent forms were performed in accordance with the Helsinki Declaration of 1964 (revised in Fortaleza, 2013) and were reviewed and approved by the Research Ethics Committee of the Government of Aragon (CEICA, Spain) [C.I. PI10/026]. The research study was registered in a public database [NCT02380638]. The CONSORT 2010 Statement was used as a guideline for reporting a randomized controlled trial[30].

\section{WBV intervention}

The training protocol and the mechanical vibration device used in this study have been described in detail elsewhere[24]. In brief, the protocol consisted of three times per week, 10 repetitions (30 to 60 seconds) with a 1-min rest, a frequency $25-30 \mathrm{~Hz}$ and an a peak-to-peak displacement of $2 \mathrm{~mm}$ for 20 weeks. The detailed schedule of training is shown in Table 1. All participants exercised, with the same trainers in each session, on a vertical vibration platform (Power Plate ${ }^{\circledR}$ Pro5; PowerPlate, Amsterdam, The Netherlands) supervised by a 
researcher during each session. The role of the researcher was to ensure safety and the correct performance (squat, bent knees at $90^{\circ}$ ) during all sets. The researcher was competent on the squatting technique due to the appropriate training, he provided verbal feedbacks when spotted a mistake. Participants were allowed to hold onto a strap during the vibration intervention. In addition to this, the researcher registered any mishap or problem throughout the intervention and kept track of the participants' attendance. Compliance was calculated as the percentage of actual time using the platform over the expected time during the 20 -week treatment period.

\section{Participants}

A parallel randomized controlled trial was conducted with a total sample of 26 adolescents; 13 with DS (6 females) and 13 without DS (5 females), between 12 and 18 years (Table 2). Participants were recruited from three different schools and institutions of Aragón (Spain). Before the start of the study, an initial interview in each institution was conducted with the participants and their parents to inform about the aims and procedures of the study as well as the possible benefits and risks derived. A written informed consent from the parents of each participant and verbal assent from the participants were obtained. An experienced cardiologist examined the adolescents with DS and gave them permission to participate in the training. Adolescents without DS were healthy and were free of medication for at least 6 months prior to the beginning of the study.

The randomization process, generated by computer, divided the sample in 2 non-equal number groups due to possible withdrawals or removals for lack of attendance. Thus, both intervention groups (DS and non-DS) received WBV training for 20 weeks being asked to avoid any change in their day-to-day lifestyle during the course of the project. Groups were as explained with the Consort Flow Diagram (Fig. 1).

\section{Anthropometric measures and puberty}


Anthropometric parameters including height, measured with a stadiometer to the nearest 0.1

$0.1 \mathrm{~kg}$ (SECA 861, SECA, Hamburg, Germany) were measured without shoes and minimal clothing following the procedures by the International Society for the Advancement in Kinanthropometry (ISAK) [31]. Body mass index $\left(\mathrm{BMI}=\right.$ weight $(\mathrm{kg}) / \mathrm{height}^{2}(\mathrm{~m})$ was determined.

All participants underwent a physical examination to determine their stage of sexual development. An expert physician classified the participants by direct observation according to the stages proposed by Tanner and Whitehouse [32].

\section{Determinations of bone}

Details of dual energy X-ray absorptiometry (DXA) measurements carried out in our laboratory have been described in previous studies [5, 24, 33]. DXA equipment was calibrated daily with a lumbar spine phantom and step densities phantom following the Hologic guidelines. The in vivo coefficient of variation in measuring BMC $(\mathrm{g})$, areal BMD $\left(\mathrm{g} / \mathrm{cm}^{2}\right)$ and bone area of the whole body in our lab were $2.3,1.3$, and $2.6 \%$, respectively measured in 49 adolescents [33].

All subjects were assessed with the pediatric version of the QDR-Explorer software (Hologic Corp. Software version 12.4, Bedford, MA 01730) while the assessments in pre- and posttraining moments were performed by the same technician who had been fully trained in the operation of the scanner, the positioning of subjects, and the analysis of results, according to the manufacturer's guidelines.

The primary outcomes were BMC and BMD measured for the whole-body (WBTOT), lumbar spine ( $\left.\mathrm{L}_{1}-\mathrm{L}_{4} ; \mathrm{SPINE}\right)$ and proximal region of the femur (hip [HIP] and femoral neck [FNECK]). In addition, subtotal (total body less head; SUBTOT), upper and lower limbs (ULIMBS and LLIMBS) and pelvis (PELV) BMC, and BMD were also determined. 


\section{Calcium intake}

Participants (parents in DS group) were specifically asked to give their current daily intake of dairy products to estimate calcium intake using a structured questionnaire. Afterwards, calcium calculations were made according to the Centro de Enseñanza Superior de Nutrición y Dietética (CESNID) tables of Spanish food composition [34].

\section{Statistical analysis}

Both, an intention-to-treat analysis which included all participants who began the protocol at baseline, and a per-protocol analysis designed to compare low- against high-compliers, were performed. The Statistical Package for the Social Sciences (SPSS) version 22.0 for Windows (SPSS Inc., Chicago, IL, USA) was used for all statistical analyses. All values shown are presented as mean (standard deviation, SD), unless otherwise stated. The sample size was based on calculations for the longitudinal study to detect a $2 \%$ change in whole body BMD, allowing for a between individual coefficient of variation in BMD of $5 \%$, with $95 \%$ confidence and $90 \%$ power. Kolmogorov-Smirnov tests showed normal distribution of the variables.

In the intention-to-treat analysis, Chi-square test was performed to evaluate differences in Tanner stage before and after the 20 weeks in both groups. Differences in physical characteristics between vibration groups (DS and non-DS) at baseline and after the training were compared with a two-independent-samples $t$-test.

Raw values for DXA measurements in pre- and post- intervention moments were compared with a two-independent-samples $t$-test and two-paired-samples $t$-test evaluated changes within each group over baseline. Thereafter, analyses of covariance (ANCOVA) were performed (adjusting by subtotal area, subtotal lean, height, calcium intake and Tanner stage for BMC and BMD parameters and by Tanner stage, weight and height for lean and fat masses) to obtain DXA values in pre- and post-training moments and calculate percentage of change. 
Two-independent-samples Student's $t$ tests were used to compare both actual changes as well as the relative (percentage) changes over time for DS and non-DS groups.

Moreover, analysis of variance (ANOVA) for repeated measures 2 (condition) x 2 (time) were performed to determine the effects of the training on body composition parameters.

The per-protocol analysis was established to identify a threshold response. In this analysis participants were classified as poor compliers (attendance below $60 \%$ ) and high compliers (attendance equal or above $60 \%$ ). It was done following the results of previous research [19, $24,35]$ showing that the some gains in bone mass after a WBV training were strongly correlated with a threshold of compliance.

Effect size were calculated for all the previous statistical tests according to the methods proposed by Cohen [36], and taking into account the cut-offs defined, the effect size can be small $(d \leq 0.2$ or $f \leq 0.1)$, medium $(d>0.2$ and $<0.8$ or $f<0.1$ and $>0.2)$, or large $(d \geq 0.8$ or $f \geq 0.4)$.

\section{Results}

Six participants, three in each group (DS and non-DS), participated only in the first assessment and consequently, data from 13 adolescents with DS and 13 without DS were analysed for the primary outcomes. The Consort Flow Diagram is shown in Fig. 1.

\section{Descriptive data}

Descriptive data regarding age, weight, height, BMI, calcium intake and Tanner stage are shown in Table 2. Adolescents with DS were smaller than non-DS adolescents at pre- and post-training moments $(d=1.21$ and $1.28 ; p=0.01$ and 0.05 , respectively).

Intention-to-treat analysis

Table 3 summarizes the results with pre- and post-training DXA values for bone mass. 
BMC at WBTOT, SUBTOT, PELV, LLIMBS, and FNECK; and BMD at PELV and HIP were significantly lower in DS group compared with non-DS group at pre- $(d=0.88$ to 1.24 ; all $p<0.05)$ and post- training moments $(d=0.88$ to 1.31 ; all $\mathrm{p}<0.05)$.

BMD at WTOT and SUBTOT showed a tendency towards differences at pre-training $(d=0.70$ and $0.79 ; p=0.05$ and 0.09 , respectively) and differences after training ( $d=0.81$ and 0.90 ; both $\mathrm{p}<0.05)$. For BMC ULIMBS and BMD LLIMBS a tendency towards differences at pre- and post-training moments were found ( $d=0.71$ to $0.79 ; \mathrm{p}=0.06$ to 0.08$)$.

In the case of HIP BMC, a significant difference was found at baseline $(d=0.88$ and $p=0.03)$ but not after the training $(d=0.80$ and $p=0.05)$, showing non-DS group higher values than DS group in both times.

After the 20 weeks of training, significant increases were found in all BMC and BMD parameters in the non-DS group ( $d z=0.66$ to 1.64 ; all $\mathrm{p}<0.05$ ), whilst DS group improved BMC at WBTOT, SUBTOT, ULIMBS, PELV, LLIMBS and SPINE ( $d z=0.75$ to 1.76 ; all $p<0.05)$ and BMD at SUBTOT, PELV, LLIMBS, and SPINE ( $d z=0.73$ to 1.28 ; all $p<0.05)$.

Table 4 presents the absolute and percentage-adjusted changes for bone DXA measures in each of the two groups. In BMC and BMD parameters, significantly greater increases were found in absolute and percentage changes of the non-DS group over DS group $(d=0.88$ to 3.85; all $p<0.05$ ). No significant condition (DS vs non-DS) by time interactions were found for any variable after the 20 weeks of training (all p>0.05). ULIMBS BMD showed a tendency towards an interaction $(f=0.41$ and $p=0.086)$ with higher increase for non-DS group.

\section{Per-protocol analysis}

Table 5 summarizes the absolute and percentage changes measured from DXA divided in condition groups, comparing by compliance to the training. There were no significant differences between groups in the absolute changes for any of these DXA measures of bone 
(all p>0.05). Highly compliant adolescents had $8.1 \%$ versus $5.3 \%$ of gains in the SPINE BMC over poorly compliant adolescents $(d=0.93$; $\mathrm{p}<0.05)$. No condition by time interactions were found for any variable (all $\mathrm{p}>0.05$ ).

\section{Discussion}

The main finding of the present study is that 20 weeks of WBV training with the proposed protocol provoke a slightly different response in adolescents with and without DS.

To date, only four studies have examined the effects of a WBV intervention in adolescents with DS, looking at balance [37], balance and muscle strength [38], fat and lean masses [24], and one at bone health [39]. Whilst the previous studies compared the effects of WBV training against a DS control group, to our knowledge, this is the first attempt of performing WBV training in adolescents with and without DS analysing and comparing the effects of this type of training on body composition.

Firstly, González-Agüero et al. [24] reported that 20-week WBV training was not enough by itself for improving lean mass in adolescents with DS. With the same intervention protocol, Matute-Llorente et al. [39] pointed out that WBV training might be useful to improve different bone parameters in clinically relevant skeletal sites in adolescents with DS and Villarroya et al. [37] found positive effects in balance of DS adolescents although only under specific conditions, whilst there were no balance improvements of those adolescents without DS. In concordance, Eid [38] showed greater improvements in stability indices and muscle strength in children with DS after 6 months of WBV and receiving a physical therapy program, than those only receiving the physical therapy program. It seems therefore realistic to affirm that young persons with DS may benefit from WBV interventions in order to improve their body composition, specifically their bone mass. 
The body composition values shown at pre- and post-training moments in this study by adolescents with DS are consistent with several previous studies [4, 6, 8, 29]. It has been welldocumented that adolescents with DS have lower levels of muscle strength and poor bonehealth, and so early interventions to stimulate muscle strength and bone accrual are of clinical importance in preventing osteoporosis [14]. Wysocki et al. [13] stated that the optimal target population for the WBV training has not been defined, while Slatkosvka et al. [40] pointed out in a meta-analysis that children and adolescents with compromised bones might be this target population. As previously stated, adolescents with DS have compromised bones so they could highly benefit from this type of intervention. This statement is also supported by a study carried out in mice with low BMD, where it was found that they were more sensitive to the mechanical stimulus than mice with normal BMD [41]; however, whether it happens in humans is yet to be elucidated.

Analysing our raw data, DS adolescents showed important increases for bone mass in several body sites such as the whole body, the limbs, the spine or the pelvis. The effects of WBV training on body composition and particularly in bone health have been also studied in other children with compromised bones such as cerebral palsy or idiopathic scoliosis [17, 22, 42]. Recently, Kilebrant et al. [42] demonstrated that WBV training had a modest effect on bone mass in children with severe motor disabilities after a 6-month intervention period. This is in accordance with another study carried out by Dalen et al. [17], who showed increased BMC at the lumbar spine as well as in both legs in children with cerebral palsy. Lam et al. [22] studied the effects of WBV training in adolescents with idiopathic scoliosis showing improvements in areal BMD at the FNECK of the dominant side and lumbar spine BMC. Despite different exercises, intensities and platforms have been used, the use of WBV training might be appropriate in disabled populations [14]. 
In the present study, adolescents without DS showed higher number of significant changes in

BMC, and BMD than those with DS. Adjusting for appropriate covariates, non-DS group still showed higher absolute changes than DS group for all bone parameters. A recent study carried out by Ferry et al. [27] showed that 1 year of training with osteogenic activities increased BMC and BMD values at the lumbar spine (7\% and $4 \%$ respectively) in children and adolescents with DS. In the present study, lower improvements were found for BMD at the whole body (3.6\% in the non-DS group and $0.9 \%$ in the DS group), but it needs to be taken into account the training period was 20 weeks (5 months) against 12-months in Ferry's study. Besides, Kilebrant et al. [42] indicated that disabled children had a reduced capacity for bone accrual due to higher carboxy-terminal telopeptides of type I collagen and lower osteocalcin values. To our knowledge, the analysis and study of biochemical markers of bone formation and resorption in adolescents with DS remain unknown. Nevertheless, in a cohort of 30 community-dwelling DS adults, McKelvet et al. [10] stated that low BMD was correlated with a significant decrease in bone formation markers, compared to controls without DS, and pointed out that diminished osteoblastic bone formation and inadequate accrual of bone mass were responsible for the low bone mass in that particular population. It would be possible to hypothesize that the low BMD and BMC values in our study can be due to increased bone resorption and/or decreased bone formation. Further studies are needed to corroborate this hypothesis.

As with any training, it may be expected that the effectiveness of the intervention is related to the compliance. The per-protocol analysis revealed greater percentage of change in the high compliers, independently of the condition, than in the low compliers, achieving the differences statistical significance for BMC at the SPINE (5.3 vs. 8.1\%). Gilsanz et al. [19] found that women with low BMD who trained at least 2 minutes per day in a WBV platform, increased up to $3.9 \%$ the trabecular bone of the spine and $2.9 \%$ the cortical bone of the 
femur. However, no additional benefits were obtained from training more than two minutes

per day and the authors suggested that a biologic response was triggered rather than accumulated based on the study carried out by Rubin et al. [43]. In our study, a $60 \%$ of attendance was established as cut-off between poor- and high-compliers. This cut-off would equal 4.2 minutes per day of WBV training, being higher than the 2-minute threshold proposed by Gilsanz et al. [19]. Important considerations should be taken into account, since Gilsanz et al. conducted a 12-month trial with the same vibration protocol $(10$ minutes, $30 \mathrm{~Hz}$, and $0.3 \mathrm{~g}$ ) which let them to establish a vibration threshold. In our study, WBV training was gradually applied increasing frequency and duration, and for that reason, further studies are needed to establish and appropriate vibration dose in DS population.

Adolescents with DS in this study attended special schools that incorporated physical activity programs over the last few years. This progress may have contributed to achieving some improvements in terms of health in the daily life of adolescents with DS but it could be interfering in our results. Despite of this, the present study suggests that WBV training has the potential to influence bone mass in reducing osteoporosis risk factors in adolescents with and without DS. In addition to this, our results might have also been influenced by the protocol used in the study. Higher intensities caused by higher peak-to-peak displacements and frequencies, the increase in the exercise intensity with unilateral exercises (one-leg Squat) or the addition of weights (i.e. $10 \%$ of body weight in a backpack) could have generated greater increases; but the proposed 20-week WBV training was chosen following the study performed by Lam et al. [22], which indicated that WBV treatment might be more efficient when it is used in a structured way, two or three times per week for 10 minutes each time. Importantly, no negative side effects were found in our study as previously indicated [14, 17, 20, 23]. This study is not exempt of limitations; firstly, the absence of a control group who would have performed the same protocol (squat position for the same amount of time) with the 
platform turned off, to observe the possible improvements due to the isometric exercise by itself. And finally, the lack of data about participants' physical activity levels could be masking some interactions with body composition. Further studies taking into account bone structure and bone metabolism markers might help to define whether an intervention of WBV alone is effective for improving body composition in population with and without DS. On the other hand, the main strength of this study is the inclusion of both genders and the use of an age-, pubertal status- and gender-matched non-DS group.

\section{Conclusion}

In conclusion, 20 weeks of WBV training with the proposed protocol may improve $\mathrm{BMC}$, and BMD in clinically relevant skeletal sites in adolescents with and without DS. Nevertheless, this type of training seems to provoke a lesser response in adolescents with DS than in those without DS suggesting that specific training and adaptations should be studied. Identifying a threshold of response, the adolescents who trained over $60 \%$ of compliance got higher increases than those under $60 \%$. Moreover, as no side effects or withdrawals were noticed during the intervention, WBV training could be defined as a safe and well-tolerated treatment in both groups.

\section{Disclosures}

Ángel Matute-Llorente, Alejandro González-Agüero, Alba Gómez-Cabello, Julio TousFajardo, Germán Vicente-Rodríguez, and José Antonio Casajús declare that they have no conflict of interest.

\section{Acknowledgments}


We gratefully acknowledge the help of all of the adolescents and their parents who participated in the study for their understanding and dedication to the project. Specials thanks are given to Fundación Down Zaragoza and Special Olympics Aragón for their support. This work was supported by "Ministerio de Ciencia e Innovación" "Plan Nacional I + D + i 2009-2011 (Project DEP 2009-09183)". This project has been co financed by "Fondo Europeo de Desarrollo Regional” (MICINN-FEDER). AML received a Grant AP12-2854 from "Ministerio de Educación Cultura y Deportes". 


\section{References}

1. Bittles AH, Glasson, EJ (2004) Clinical, social, and ethical implications of changing life expectancy in Down syndrome. Dev Med Child Neurol 46:282-286.

2. (1993) Consensus development conference: diagnosis, prophylaxis, and treatment of osteoporosis. Am J Med 94:646-650.

3. Sakadamis A, Angelopoulou, N, Matziari, C, Papameletiou, V, Souftas, V (2002) Bone mass, gonadal function and biochemical assessment in young men with trisomy 21. Eur J Obstet Gynecol Reprod Biol 100:208-212.

4. Baptista F, Varela, A, Sardinha, LB (2005) Bone mineral mass in males and females with and without Down syndrome. Osteoporos Int 16:380-388.

5. González-Agüero A, Vicente-Rodríguez, G, Moreno, LA, Casajús, JA (2011) Bone mass in male and female children and adolescents with Down syndrome. Osteoporos Int 22:2151-2157.

6. Guijarro M, Valero, C, Paule, B, Gonzalez-Macias, J, Riancho, JA (2008) Bone mass in young adults with Down syndrome. J Intellect Disabil Res 52:182-189.

7. Angelopoulou N, Souftas, V, Sakadamis, A, Mandroukas, K (1999) Bone mineral density in adults with Down's syndrome. Eur Radiol 9:648-651.

8. Geijer JR, Stanish, HI, Draheim, CC, Dengel, DR (2014) Bone mineral density in adults with Down syndrome, intellectual disability, and nondisabled adults. Am J Intellect Dev Disabil 119:107114.

9. Lips P (1997) Epidemiology and predictors of fractures associated with osteoporosis. Am J Med 103:3S-8S; discussion 8S-11S.

10. McKelvey KD, Fowler, TW, Akel, NS, Kelsay, JA, Gaddy, D, Wenger, GR, Suva, LJ (2013) Low bone turnover and low bone density in a cohort of adults with Down syndrome. Osteoporos Int 24:1333-1338.

11. Bauman AE (2004) Updating the evidence that physical activity is good for health: an epidemiological review 2000-2003. J Sci Med Sport 7:6-19.

12. Vicente-Rodriguez G (2006) How does exercise affect bone development during growth? Sports Med 36:561-569.

13. Wysocki A, Butler, M, Shamliyan, T, Kane, RL (2011) Whole-body vibration therapy for osteoporosis: state of the science. Ann Intern Med 155:680-686, W206-613.

14. Matute-Llorente A, González-Agüero, A, Gómez-Cabello, A, Vicente-Rodríguez, G, Casajús, JA (2013) Effect of Whole-Body Vibration Therapy on Health-Related Physical Fitness in Children and Adolescents With Disabilities: A Systematic Review. J Adolesc Health 54:385-396.

15. Gomez-Cabello A, Gonzalez-Aguero, A, Morales, S, Ara, I, Casajus, JA, Vicente-Rodriguez, G (2014) Effects of a short-term whole body vibration intervention on bone mass and structure in elderly people. J Sci Med Sport 17:160-164.

16. Gomez-Cabello A, Ara, I, Gonzalez-Aguero, A, Casajus, JA, Vicente-Rodriguez, G (2012) Effects of training on bone mass in older adults: a systematic review. Sports Med 42:301-325.

17. Dalen Y, Sääf, M, Nyrén, S, Mattsson, E, Haglund-Akerlind, Y, Klefbeck, B (2012) Observations of four children with severe cerebral palsy using a novel dynamic platform. A case report. Adv Physiother 14:132-139.

18. Ruck J, Chabot, G, Rauch, F (2010) Vibration treatment in cerebral palsy: A randomized controlled pilot study. J Musculoskelet Neuronal Interact 10:77-83.

19. Gilsanz V, Wren, TA, Sanchez, M, Dorey, F, Judex, S, Rubin, C (2006) Low-level, highfrequency mechanical signals enhance musculoskeletal development of young women with low BMD. J Bone Miner Res 21:1464-1474.

20. Ward K, Alsop, C, Caulton, J, Rubin, C, Adams, J, Mughal, Z (2004) Low magnitude mechanical loading is osteogenic in children with disabling conditions. J Bone Miner Res 19:360-369. 
21. Pitukcheewanont P, Safani, D (2006) Extremely low-level, short-term mechanical stimulation increases cancellous and cortical bone density and muscle mass of children with low bone density: A pilot study. The Endocrinologist 16:128-132.

22. Lam TP, Ng, BK, Cheung, LW, Lee, KM, Qin, L, Cheng, JC (2012) Effect of whole body vibration (WBV) therapy on bone density and bone quality in osteopenic girls with adolescent idiopathic scoliosis: a randomized, controlled trial. Osteoporos Int 24:1623-1636.

23. Soderpalm AC, Kroksmark, AK, Magnusson, P, Karlsson, J, Tulinius, M, Swolin-Eide, D (2013) Whole body vibration therapy in patients with Duchenne muscular dystrophy - A prospective observational study. J Musculoskelet Neuronal Interact 13:13-18.

24. González-Agüero A, Matute-Llorente, A, Gómez-Cabello, A, Casajús, JA, Vicente-Rodríguez, G (2013) Effects of whole body vibration training on body composition in adolescents with Down syndrome. Res Dev Disabil 34:1426-1433.

25. González-Agüero A, Vicente-Rodríguez, G, Gómez-Cabello, A, Ara, I, Moreno, LA, Casajús, JA (2012) A 21-week bone deposition promoting exercise programme increases bone mass in young people with Down syndrome. Dev Med Child Neurol 54:552-556.

26. González-Agüero A, Vicente-Rodríguez, G, Gómez-Cabello, A, Ara, I, Moreno, LA, Casajús, JA (2011) A combined training intervention programme increases lean mass in youths with Down syndrome. Res Dev Disabil 32:2383-2388.

27. Ferry B, Gavris, M, Tifrea, C, Serbanoiu, S, Pop, AC, Bembea, M, Courteix, D (2014) The bone tissue of children and adolescents with Down syndrome is sensitive to mechanical stress in certain skeletal locations: a 1-year physical training program study. Res Dev Disabil 35:2077-2084.

28. Reza SM, Rasool, H, Mansour, S, Abdollah, H (2013) Effects of calcium and training on the development of bone density in children with Down syndrome. Res Dev Disabil 34:4304-4309.

29. González-Agüero A, Vicente-Rodríguez, G, Moreno, LA, Guerra-Balic, M, Ara, I, Casajús, JA (2010) Health-related physical fitness in children and adolescents with Down syndrome and response to training. Scand J Med Sci Sports 20:716-724.

30. Moher D, Hopewell, S, Schulz, KF, Montori, V, Gotzsche, PC, Devereaux, PJ, Elbourne, D, Egger, M, Altman, DG (2012) CONSORT 2010 explanation and elaboration: updated guidelines for reporting parallel group randomised trials. Int J Surg 10:28-55.

31. Marfell-Jones M (2006) International standards for anthropometric assessment. International Society for the Advancement of Kinanthropometry, Potchefstroom, South Africa.

32. Tanner JM, Whitehouse, RH (1976) Clinical longitudinal standards for height, weight, height velocity, weight velocity, and stages of puberty. Arch Dis Child 51:170-179.

33. Gracia-Marco L, Ortega, FB, Jimenez-Pavon, D, Rodriguez, G, Castillo, MJ, Vicente-Rodriguez, G, Moreno, LA (2012) Adiposity and bone health in Spanish adolescents. The HELENA study. Osteoporos Int 23:937-947.

34. Farran A, Zamora, R, Cervera, P (2004) Tablas de composición de alimentos del CESNID. McGraw-Hill/Interamericana de España, S.A.U. Ediciones Universitat de Barcelona.

35. Wren TA, Lee, DC, Hara, R, Rethlefsen, SA, Kay, RM, Dorey, FJ, Gilsanz, V (2010) Effect of highfrequency, low-magnitude vibration on bone and muscle in children with cerebral palsy. J Pediatr Orthop 30:732-738.

36. Cohen J (1969) Statistical power analysis for the behavioural sciences. Academic Press, New York.

37. Villarroya MA, Gonzalez-Aguero, A, Moros, T, Gomez-Trullen, E, Casajus, JA (2013) Effects of whole body vibration training on balance in adolescents with and without Down syndrome. Res Dev Disabil 34:3057-3065.

38. Eid MA (2014) Effect of Whole-Body Vibration Training on Standing Balance and Muscle Strength in Children with Down Syndrome. Am J Phys Med Rehabil.

39. Matute-Llorente A, Gonzalez-Aguero, A, Gomez-Cabello, A, Olmedillas, H, Vicente-Rodriguez, G, Casajus, JA (2015) Effect of whole body vibration training on bone mineral density and bone quality in adolescents with Down syndrome: a randomized controlled trial. Osteoporos Int. 
40. Slatkovska L, Alibhai, SM, Beyene, J, Cheung, AM (2010) Effect of whole-body vibration on BMD: a systematic review and meta-analysis. Osteoporos Int 21:1969-1980.

41. Judex S, Donahue, LR, Rubin, C (2002) Genetic predisposition to low bone mass is paralleled by an enhanced sensitivity to signals anabolic to the skeleton. Faseb J 16:1280-1282.

42. Kilebrant S, Braathen, G, Emilsson, R, Glansen, U, Soderpalm, AC, Zetterlund, B, Westerberg, $B$, Magnusson, P, Swolin-Eide, D (2015) Whole-body vibration therapy in children with severe motor disabilities. J Rehabil Med 47:223-228.

43. Rubin CT, Lanyon, LE (1984) Regulation of bone formation by applied dynamic loads. J Bone Joint Surg Am 66:397-402. 
Fig. 1. Consort flow diagram of the follow-up of the participants

1

2

3

4

5

8

10

11

12

13

14

15

16

17

18

19

20

21

22

23

24

25

26

27

28

29

30

31

32

33

34

35

36

37

38

39

40

41

42

43

44

45

46

47

48

49

50

51

52

53

54

55

56

57

58

59

60

61

62

63

64

65 
Table 1 Protocol for WBV groups three times per week.

$\begin{array}{cccccccc}\text { Sessions } & \text { Frequency } & \text { Peak-to-peak } & \text { Duration } & \text { Rest Repetitions } & \text { Vibration total } & \text { Training total } & \text { Peak } \\ & (\mathrm{Hz}) & \text { displacement } & (\mathrm{s}) & (\mathrm{s}) & \text { time }(\mathrm{min}) & \text { time }(\mathrm{min}) & \text { acceleration }\end{array}$

\begin{tabular}{|c|c|c|c|c|c|c|c|c|c|}
\hline & & & $(\mathrm{mm})$ & & & & & & (g) \\
\hline Month 1 & 12 & 25 & 2 & 30 & 60 & 10 & 5 & 15 & 2.5 \\
\hline Month 2 & 12 & 28 & 2 & 30 & 60 & 10 & 5 & 15 & 3.2 \\
\hline Month 3 & 12 & 28 & 2 & 45 & 60 & 10 & 7.5 & 17.5 & 3.2 \\
\hline Month 4 & 12 & 28 & 2 & 45 & 60 & 10 & 7.5 & 17.5 & 3.2 \\
\hline Month 5 & 12 & 30 & 2 & 60 & 60 & 10 & 10 & 20 & 3.6 \\
\hline
\end{tabular}


Table 2 Pre-training physical characteristics of the participants.

\begin{tabular}{|c|c|c|c|c|c|c|c|c|c|c|c|c|}
\hline & \multicolumn{6}{|c|}{ Pre-training } & \multicolumn{6}{|c|}{ Post-training } \\
\hline & \multicolumn{2}{|c|}{$\begin{array}{c}\text { DS } \\
(n=13)\end{array}$} & \multicolumn{2}{|c|}{$\begin{array}{l}\text { non-DS } \\
(\mathrm{n}=13)\end{array}$} & \multirow{2}{*}{$\begin{array}{c}\text { Student's t } \\
\mathrm{p}\end{array}$} & \multirow{2}{*}{$\begin{array}{c}\text { Cohen's } \\
\text { d }\end{array}$} & \multicolumn{2}{|l|}{$\begin{array}{c}\text { DS } \\
(\mathrm{n}=13)\end{array}$} & \multicolumn{2}{|c|}{$\begin{array}{l}\text { non-DS } \\
(\mathrm{n}=13)\end{array}$} & \multirow{2}{*}{$\begin{array}{c}\text { Student's t } \\
\mathrm{p}\end{array}$} & \multirow{2}{*}{$\begin{array}{c}\text { Cohen's } \\
\mathrm{d}\end{array}$} \\
\hline & Mean & SD & Mean & SD & & & Mean & SD & Mean & SD & & \\
\hline Weight (kg) & 48.4 & 9.2 & 56.6 & 16.1 & 0.127 & 0.62 & 49.3 & 9.3 & 58.8 & 15.6 & 0.071 & 0.73 \\
\hline Height $(\mathrm{cm})$ & 148.1 & 8.0 & 162.4 & 16.4 & 0.012 & 1.21 & 148.8 & 7.3 & 164.5 & 15.7 & 0.005 & 1.28 \\
\hline BMI $\left(\mathrm{kg} / \mathrm{m}^{2}\right)$ & 21.9 & 3.4 & 21.0 & 2.9 & 0.459 & 0.28 & 22.1 & 3.5 & 21.3 & 2.8 & 0.522 & 0.25 \\
\hline $\begin{array}{l}\text { Calcium Intake } \\
\text { (mg/day) }\end{array}$ & & & & & $\begin{array}{l}\text { Chi-square } \\
\text { sig. }\end{array}$ & & & & & & $\begin{array}{c}\text { Chi-square } \\
\text { sig. }\end{array}$ & \\
\hline $\begin{array}{l}\text { Tanner stage } \\
\text { (I/II/III/IV/V) }\end{array}$ & \multicolumn{2}{|c|}{$0 / 1 / 2 / 3 / 7$} & \multicolumn{2}{|c|}{$1 / 2 / 4 / 0 / 6$} & 0.279 & - & \multicolumn{2}{|l|}{$0 / 1 / 2 / 2 / 8$} & \multicolumn{2}{|c|}{$1 / 1 / 4 / 1 / 6$} & 0.683 & - \\
\hline
\end{tabular}

DS Down syndrome group, non-DS non-Down syndrome group, BMI body mass index. $d=$ Effect size conventions, small $(d \leq 0.2)$, medium $(d>0.2$ and $<0.8)$, or large $(d \geq 0.8)$. 
Table 3 Pre- and post-training bone values for both non-DS and DS groups ( $\mathrm{N}=13$ in each group).

\begin{tabular}{|c|c|c|c|c|c|c|c|c|c|c|c|c|c|c|c|c|c|}
\hline & & \multicolumn{6}{|c|}{$\mathrm{DS}$} & \multicolumn{6}{|c|}{ non-DS } & \multicolumn{4}{|c|}{ Independent $t$ test } \\
\hline & & \multicolumn{2}{|c|}{ Pre-training } & \multicolumn{2}{|c|}{ Post-training } & \multicolumn{2}{|c|}{ Paired $t$ test } & \multicolumn{2}{|c|}{ Pre-training } & \multicolumn{2}{|c|}{ Post-training } & \multicolumn{2}{|c|}{ Paired $t$ test } & \multicolumn{2}{|c|}{$\begin{array}{c}\text { Pre- } \\
\text { training }\end{array}$} & \multicolumn{2}{|c|}{$\begin{array}{c}\text { Post- } \\
\text { training }\end{array}$} \\
\hline & & Mean & SD & Mean & SD & $p$ & $d z$ & Mean & $\mathrm{SD}$ & Mean & SD & $p$ & $d z$ & $p$ & $d$ & $p$ & $d$ \\
\hline \multirow{8}{*}{$\begin{array}{c}\text { BMC } \\
(\mathrm{g})\end{array}$} & WBTOT & 1453.87 & 272.36 & 1505.56 & 268.48 & 0.006 & 0.90 & 1983.40 & 756.38 & 2129.24 & 785.74 & $<0.001$ & 1.63 & 0.031 & 0.93 & 0.016 & 1.06 \\
\hline & SUBTOT & 1077.24 & 212.52 & 1131.06 & 201.89 & $<0.001$ & 1.32 & 1533.58 & 632.17 & 1630.25 & 644.95 & $<0.001$ & 1.48 & 0.026 & 0.96 & 0.018 & 1.04 \\
\hline & ULIMBS & 185.14 & 42.11 & 193.71 & 36.13 & 0.019 & 0.75 & 238.80 & 97.51 & 252.69 & 98.34 & 0.006 & 0.91 & 0.087 & 0.71 & 0.060 & 0.79 \\
\hline & PELV & 144.03 & 32.34 & 153.83 & 33.63 & 0.018 & 0.76 & 219.95 & 112.82 & 248.64 & 118.87 & $<0.001$ & 1.64 & 0.035 & 0.91 & 0.015 & 1.08 \\
\hline & LLIMBS & 494.92 & 105.98 & 521.66 & 102.56 & $<0.001$ & 1.76 & 792.06 & 325.51 & 838.72 & 326.94 & $<0.001$ & 1.30 & 0.007 & 1.22 & 0.005 & 1.30 \\
\hline & SPINE & 41.52 & 8.96 & 44.04 & 8.50 & 0.005 & 0.94 & 47.27 & 18.89 & 50.52 & 18.94 & $<0.001$ & 1.35 & 0.335 & 0.38 & 0.276 & 0.44 \\
\hline & FNECK & 3.21 & 0.58 & 3.26 & 0.59 & 0.567 & 0.19 & 4.10 & 1.32 & 4.44 & 1.36 & $<0.001$ & 1.49 & 0.042 & 0.87 & 0.011 & 1.12 \\
\hline & HIP & 23.44 & 5.75 & 26.15 & 9.44 & 0.144 & 0.43 & 32.20 & 12.80 & 35.60 & 13.62 & 0.001 & 1.22 & 0.038 & 0.88 & 0.052 & 0.80 \\
\hline \multirow{8}{*}{$\begin{array}{c}\text { BMD } \\
\left(\mathrm{g} / \mathrm{cm}^{2}\right)\end{array}$} & WBTOT & 0.933 & 0.083 & 0.941 & 0.078 & 0.169 & 0.38 & 1.031 & 0.178 & 1.068 & 0.182 & $<0.001$ & 1.43 & 0.091 & 0.70 & 0.035 & 0.90 \\
\hline & SUBTOT & 0.803 & 0.071 & 0.819 & 0.066 & 0.001 & 1.28 & 0.905 & 0.167 & 0.931 & 0.165 & 0.002 & 1.10 & 0.059 & 0.79 & 0.037 & 0.81 \\
\hline & ULIMBS & 1.290 & 0.128 & 1.304 & 0.118 & 0.176 & 0.41 & 1.321 & 0.182 & 1.350 & 0.169 & 0.009 & 0.85 & 0.630 & 0.19 & 0.433 & 0.31 \\
\hline & PELV & 0.862 & 0.080 & 0.882 & 0.073 & 0.022 & 0.73 & 1.024 & 0.219 & 1.067 & 0.223 & 0.007 & 0.90 & 0.025 & 0.98 & 0.013 & 1.11 \\
\hline & LLIMBS & 1.994 & 0.217 & 2.046 & 0.214 & 0.003 & 1.01 & 2.257 & 0.461 & 2.321 & 0.449 & 0.012 & 0.83 & 0.080 & 0.72 & 0.063 & 0.78 \\
\hline & SPINE & 0.820 & 0.106 & 0.844 & 0.105 & 0.015 & 0.80 & 0.858 & 0.166 & 0.887 & 0.169 & 0.009 & 0.88 & 0.493 & 0.27 & 0.445 & 0.30 \\
\hline & FNECK & 0.760 & 0.100 & 0.791 & 0.170 & 0.267 & 0.31 & 0.831 & 0.134 & 0.866 & 0.158 & 0.003 & 1.08 & 0.137 & 0.60 & 0.261 & 0.45 \\
\hline & HIP & 0.812 & 0.090 & 0.846 & 0.129 & 0.062 & 0.57 & 0.922 & 0.141 & 0.970 & 0.150 & 0.001 & 1.21 & 0.027 & 0.92 & 0.033 & 0.88 \\
\hline
\end{tabular}

DS Down syndrome group, non-DS non-Down syndrome group, BMC bone mineral content, WBTOT total whole-body, SUBTOT subtotal body (total body less head), ULIMBS upper limbs, PELV pelvis, LLIMBS lower limbs, SPINE lumbar spine, FNECK femoral neck, HIP total hip, BMD bone mineral density.

$d=$ Effect size conventions, small $(d \leq 0.2)$, medium $(d>0.2$ and $<0.8)$, or large $(d \geq 0.8)$. 
Table 4 Absolute and percent adjusted-change in bone DXA measures for both non-DS and DS groups (N=13 in each group).

\begin{tabular}{|c|c|c|c|c|c|c|c|c|c|c|c|c|c|c|c|}
\hline & & \multicolumn{6}{|c|}{ Absolute change } & \multicolumn{6}{|c|}{ Percent change } & \multirow{2}{*}{\multicolumn{2}{|c|}{$\begin{array}{c}\text { Repeated } \\
\text { measures } \\
\text { Condition } \\
\text { by time }\end{array}$}} \\
\hline & & \multicolumn{2}{|c|}{ DS } & \multicolumn{2}{|c|}{ non-DS } & \multicolumn{2}{|c|}{$\begin{array}{c}\text { Independent } \\
t \text { test }\end{array}$} & \multicolumn{2}{|c|}{ DS } & \multicolumn{2}{|c|}{ non-DS } & \multicolumn{2}{|c|}{$\begin{array}{c}\text { Independent } \\
t \text { test }\end{array}$} & & \\
\hline & & Mean & SD & Mean & SD & $p$ & $d$ & Mean & SD & Mean & SD & $p$ & $d$ & $p$ & $f$ \\
\hline \multirow{8}{*}{$\begin{array}{c}\text { BMC } \\
(\mathrm{g})\end{array}$} & WBTOT & 51.68 & 28.56 & 145.83 & 36.38 & $<0.001$ & 2.87 & 3.69 & 2.35 & 7.92 & 2.31 & $<0.001$ & 1.81 & 0.797 & 0.20 \\
\hline & SUBTOT & 53.81 & 35.69 & 96.66 & 32.66 & 0.004 & 1.25 & 5.42 & 4.45 & 7.25 & 3.67 & 0.264 & 0.44 & 0.192 & 0.31 \\
\hline & ULIMBS & 8.57 & 5.89 & 13.89 & 6.07 & 0.033 & 0.88 & 4.91 & 3.47 & 7.10 & 4.25 & 0.163 & 0.56 & 0.984 & 0.03 \\
\hline & PELV & 9.80 & 5.88 & 28.69 & 9.09 & $<0.001$ & 2.46 & 7.06 & 4.29 & 14.72 & 5.80 & 0.001 & 1.50 & 0.628 & 0.11 \\
\hline & LLIMBS & 26.73 & 13.86 & 46.66 & 12.19 & 0.001 & 1.52 & 5.96 & 4.17 & 6.94 & 3.56 & 0.526 & 0.25 & 0.558 & 0.13 \\
\hline & SPINE & 2.52 & 1.20 & 3.25 & 0.91 & 0.095 & 0.68 & 6.59 & 3.74 & 7.95 & 4.24 & 0.396 & 0.34 & 0.709 & 0.08 \\
\hline & FNECK & 0.04 & 0.09 & 0.34 & 0.09 & $<0.001$ & 3.33 & 1.46 & 3.01 & 9.02 & 3.96 & $<0.001$ & 2.14 & 0.463 & 0.17 \\
\hline & HIP & 2.70 & 2.18 & 3.39 & 1.75 & 0.380 & 0.34 & 11.95 & 8.63 & 10.98 & 4.82 & 0.727 & 0.13 & 0.711 & 0.08 \\
\hline \multirow{8}{*}{$\begin{array}{l}\text { BMD } \\
\left(\mathrm{g} / \mathrm{cm}^{2}\right)\end{array}$} & WBTOT & 0.008 & 0.008 & 0.037 & 0.007 & $<0.001$ & 3.85 & 0.93 & 0.86 & 3.65 & 0.81 & $<0.001$ & 3.25 & 0.264 & 0.26 \\
\hline & SUBTOT & 0.016 & 0.011 & 0.025 & 0.010 & 0.029 & 0.85 & 2.05 & 1.62 & 3.00 & 1.44 & 0.129 & 0.61 & 0.458 & 0.17 \\
\hline & ULIMBS & 0.013 & 0.007 & 0.029 & 0.021 & 0.029 & 1.02 & 1.06 & 0.60 & 2.41 & 1.89 & 0.027 & 0.96 & 0.086 & 0.41 \\
\hline & PELV & 0.020 & 0.021 & 0.043 & 0.021 & 0.013 & 1.09 & 2.41 & 2.76 & 4.22 & 1.93 & 0.065 & 0.76 & 0.156 & 0.33 \\
\hline & LLIMBS & 0.052 & 0.032 & 0.064 & 0.027 & 0.329 & 0.40 & 2.69 & 1.76 & 3.05 & 1.58 & 0.590 & 0.21 & 0.462 & 0.17 \\
\hline & SPINE & 0.023 & 0.013 & 0.028 & 0.008 & 0.290 & 0.46 & 2.94 & 1.75 & 3.49 & 1.52 & 0.405 & 0.33 & 0.993 & 0.01 \\
\hline & FNECK & 0.031 & 0.030 & 0.034 & 0.026 & 0.810 & 0.10 & 4.05 & 3.91 & 3.98 & 2.68 & 0.953 & 0.02 & 0.369 & 0.21 \\
\hline & HIP & 0.033 & 0.018 & 0.047 & 0.019 & 0.069 & 0.75 & 4.11 & 2.21 & 5.11 & 1.75 & 0.216 & 0.50 & 0.815 & 0.05 \\
\hline
\end{tabular}

DS Down syndrome group, non-DS non-Down syndrome group, BMC bone mineral content, WBTOT total whole-body, SUBTOT subtotal body (total body less head), ULIMBS upper limbs, PELV pelvis, LLIMBS lower limbs, SPINE lumbar spine, FNECK femoral neck, HIP total hip, BMD bone mineral density.

Repeated measures $p$ values are obtained from the condition by time interactions adjusting by subtotal bone area, subtotal lean mass, height, calcium intake, and Tanner stage.

$d$ and $f=$ Effect size conventions, small $(d \leq 0.2$ or $f \leq 0.1)$, medium $(d>0.2$ and $<0.8$ or $f<0.1$ and $>0.2)$, or large $(d \geq 0.8$ or $f \geq 0.4$ ). 
Table 5 Using a per protocol analysis, the absolute and percent changes measured from DXA were compared between the poor compliers (lower than $60 \%$ of compliance, $\mathrm{N}=8$ ) and the high compliers (higher than $60 \%, \mathrm{~N}=18$ ).

\begin{tabular}{|c|c|c|c|c|c|c|c|c|c|c|c|c|c|c|c|}
\hline & & \multicolumn{6}{|c|}{ Absolute change } & \multicolumn{6}{|c|}{ Percent change } & \multirow{2}{*}{\multicolumn{2}{|c|}{$\begin{array}{c}\text { Repeated } \\
\text { measures } \\
\text { Condition by } \\
\text { time }\end{array}$}} \\
\hline & & \multicolumn{2}{|c|}{ Poor compliers } & \multicolumn{2}{|c|}{$\begin{array}{l}\text { High } \\
\text { compliers }\end{array}$} & \multicolumn{2}{|c|}{$\begin{array}{c}\text { Independent } t \\
\text { test }\end{array}$} & \multicolumn{2}{|c|}{$\begin{array}{l}\text { Poor } \\
\text { compliers }\end{array}$} & \multicolumn{2}{|c|}{$\begin{array}{l}\text { High } \\
\text { compliers }\end{array}$} & \multicolumn{2}{|c|}{$\begin{array}{l}\text { Independent } t \\
\text { test }\end{array}$} & & \\
\hline & & Mean & SD & Mean & SD & $p$ & $d$ & Mean & $\mathrm{SD}$ & Mean & SD & $p$ & $d$ & $p$ & $f$ \\
\hline \multirow{8}{*}{$\begin{array}{c}\text { BMC } \\
(\mathrm{g})\end{array}$} & WBTOT & 105.96 & 68.68 & 95.56 & 54.05 & 0.680 & 0.16 & 4.85 & 2.24 & 6.22 & 3.44 & 0.315 & 0.48 & 0.894 & 0.03 \\
\hline & SUBTOT & 72.78 & 41.52 & 76.33 & 40.49 & 0.839 & 0.08 & 4.49 & 1.88 & 7.15 & 4.58 & 0.130 & 0.82 & 0.896 & 0.03 \\
\hline & ULIMBS & 10.39 & 5.82 & 11.60 & 6.85 & 0.667 & 0.19 & 4.30 & 2.77 & 6.76 & 4.24 & 0.148 & 0.70 & 0.740 & 0.07 \\
\hline & PELV & 20.10 & 16.92 & 18.86 & 10.04 & 0.852 & 0.09 & 8.01 & 5.65 & 12.17 & 6.35 & 0.125 & 0.69 & 0.509 & 0.15 \\
\hline & LLIMBS & 35.26 & 15.13 & 37.33 & 17.22 & 0.772 & 0.12 & 4.75 & 1.49 & 7.20 & 4.32 & 0.135 & 0.84 & 0.989 & 0.03 \\
\hline & SPINE & 2.79 & 0.96 & 2.93 & 1.19 & 0.771 & 0.13 & 5.37 & 1.41 & 8.12 & 4.47 & 0.028 & 0.93 & 0.188 & 0.31 \\
\hline & FNECK & 0.16 & 0.20 & 0.20 & 0.16 & 0.654 & 0.22 & 3.52 & 4.64 & 6.00 & 5.33 & 0.267 & 0.49 & 0.277 & 0.25 \\
\hline & HIP & 3.18 & 2.31 & 2.99 & 1.86 & 0.823 & 0.09 & 9.68 & 7.23 & 12.26 & 6.75 & 0.388 & 0.36 & 0.232 & 0.28 \\
\hline \multirow{8}{*}{$\begin{array}{l}\mathrm{BMD} \\
\left(\mathrm{g} / \mathrm{cm}^{2}\right)\end{array}$} & WBTOT & 0.023 & 0.018 & 0.022 & 0.016 & 0.863 & 0.05 & 2.14 & 1.52 & 2.36 & 1.68 & 0.762 & 0.13 & 0.321 & 0.23 \\
\hline & SUBTOT & 0.017 & 0.008 & 0.022 & 0.012 & 0.311 & 0.50 & 1.84 & 0.85 & 2.83 & 1.74 & 0.063 & 0.76 & 0.200 & 0.30 \\
\hline & ULIMBS & 0.014 & 0.017 & 0.024 & 0.017 & 0.203 & 0.58 & 1.13 & 1.40 & 2.01 & 1.55 & 0.183 & 0.59 & 0.055 & 0.46 \\
\hline & PELV & 0.032 & 0.027 & 0.031 & 0.023 & 0.917 & 0.04 & 2.94 & 2.21 & 3.49 & 2.67 & 0.621 & 0.22 & 0.914 & 0.03 \\
\hline & LLIMBS & 0.046 & 0.022 & 0.063 & 0.031 & 0.174 & 0.65 & 2.01 & 0.99 & 3.26 & 1.76 & 0.077 & 0.91 & 0.836 & 0.04 \\
\hline & SPINE & 0.022 & 0.007 & 0.027 & 0.012 & 0.373 & 0.55 & 2.54 & 0.89 & 3.51 & 1.81 & 0.165 & 0.71 & 0.188 & 0.31 \\
\hline & FNECK & 0.039 & 0.026 & 0.029 & 0.028 & 0.429 & 0.37 & 4.70 & 3.11 & 3.71 & 3.40 & 0.493 & 0.30 & 0.529 & 0.14 \\
\hline & HIP & 0.040 & 0.025 & 0.040 & 0.017 & 0.952 & 0.01 & 4.25 & 2.46 & 4.77 & 1.85 & 0.553 & 0.24 & 0.419 & 0.19 \\
\hline
\end{tabular}

DS Down syndrome group, non-DS non-Down syndrome group, BMC bone mineral content, WBTOT total whole-body, SUBTOT subtotal body (total body less head), ULIMBS upper limbs, PELV pelvis, LLIMBS lower limbs, SPINE lumbar spine, FNECK femoral neck, HIP total hip, BMD bone mineral density.

$d$ and $f=$ Effect size conventions, small $(d \leq 0.2$ or $f \leq 0.1)$, medium $(d>0.2$ and $<0.8$ or $f<0.1$ and $>0.2)$, or large $(d \geq 0.8$ or $f \geq 0.4$ ). 


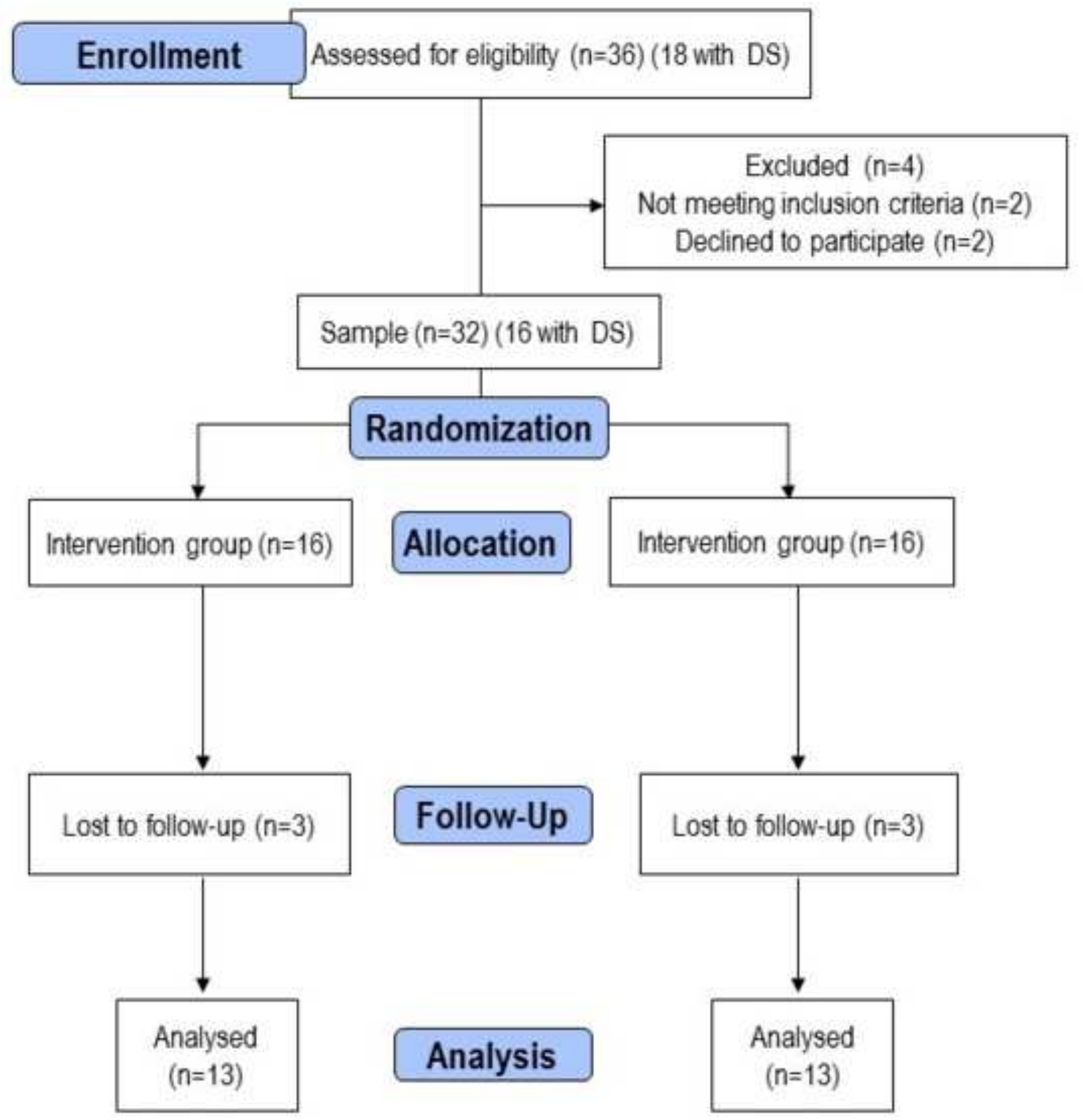




\title{
OSTEOPOROSIS INTERNATIONAL Authorship \& Disclosure Form
}

Effect of whole-body vibration training on bone mass in adolescents with and without Down syndrome: a randomized controlled trial

\author{
Article Title (first few words) \\ First Author: Matute-Llorente Angel \\ E-mail: amatute@unizar.es
}

After submission of this agreement signed by all authors, changes of authorship or in the order of the authors listed will not be accepted by Springer.

\section{AUTHORSHIP}

I, the undersigned author(s), certify that:

- I have seen and approved the final version of the manuscript, and all subsequent versions.

- I have made substantial contributions to conception and design, or acquisition of data, or analysis and interpretation of data;

- I have drafted the article or revised it critically for important intellectual content.

I accept public responsibility for it, and believe it represents valid work. As an author of this article, I also certify that none of the material in the manuscript has been previously published, nor is it included in any other manuscript. I certify that this manuscript is not under consideration for publication elsewhere, nor has it been submitted or accepted in another publication in any form. The rights or interest in the manuscript have not been assigned to any third party.

Moreover, should the editor of Osteoporosis International request the data upon which the manuscript is based, I shall produce it. I also certify that I have read and complied with the copyright information, as found on the Osteoporosis International home page website.

\section{FINANCIAL DISCLOSURE/CONFLICT OF INTEREST}

I certify that any financial interests such as employment, stock ownership, honoraria, paid expert testimony, as well as any personal relationships, academic competition, and intellectual passion which may inappropriately influence my actions, have been disclosed on a separate attachment.

All funding sources supporting the work and all institutional or corporate affiliations of mine are acknowledged in a footnote.

I have had full access to all the data in the study (if applicable) and thereby accept full responsibility for the integrity of the data and the accuracy of the data analysis.

By checking the box next to my signature I assert that there are no conflicts of interest (both personal and institutional) regarding specific financial interests that are relevant to the work conducted or reported in this manuscript.

\section{PLEASE NOTE}

1. Every author must sign the Authorship \& Disclosure form.

2. It is possible to submit more than one form if the authors are in several locations.

3. All forms must be submitted at the same time.

4. Completed forms must be scanned and included as a pdf file during the online submission process as a supplemental file not for review.

Please email any queries to the appropriate Managing Editor: European Office: Fina Liu - oi.europe@iofbonehealth.org USA Office: Adrianne Tewksbury - tewksburya@helenhayeshosp.org 


\section{OSTEOPOROSIS INTERNATIONAL Authorship \& Disclosure Form}

MANUSCRIPT ID NUMBER (IF KNOWN)
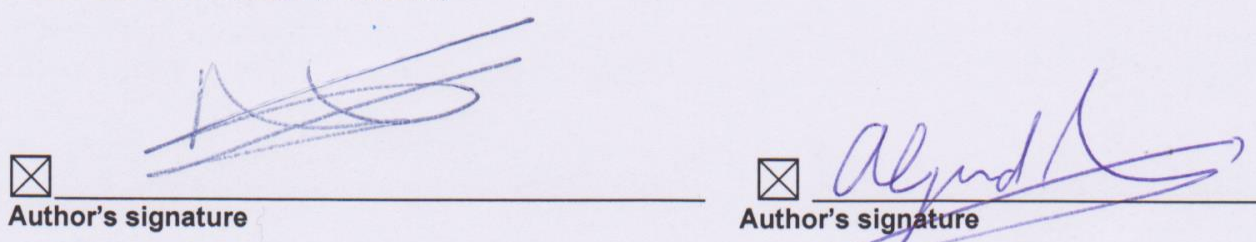

A'ngel Matute-Ulorente 8-5-2015

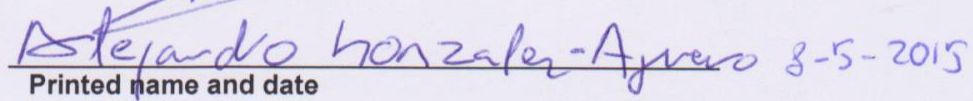
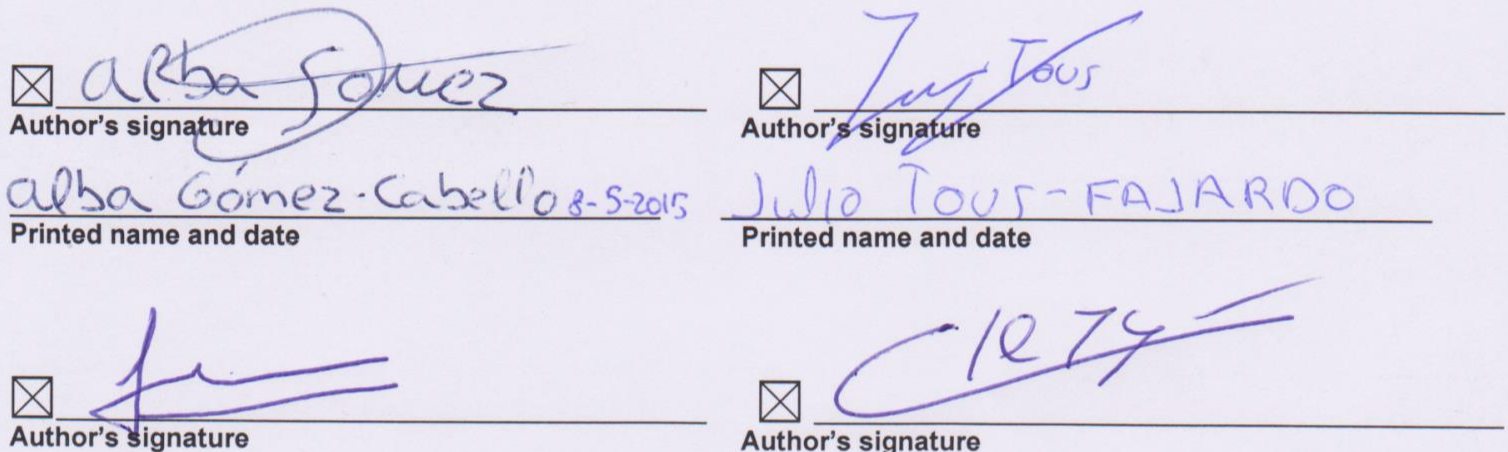

$X$

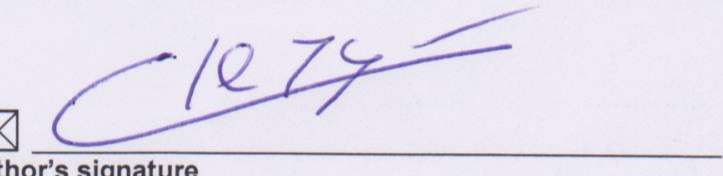

German VICENTE-RODRI6UE2 8-5-2a Printed name and date

Author's signature

Author's signature

Author's signature

Printed name and date

Printed name and date

Author's signature

Author's signature

Printed name and date

Printed name and date

Author's signature

Author's signature

Printed name and date

Printed name and date

Page 2 of 2- (signatures $\&$ dates required on page 2) 